CRISTÓBAL VALLEJOS FABRES

DEPARTAMENTO DE DISEÑO

FACULTAD DE ARQUITECTURA Y URBANISMO

UNIVERSIDAD DE CHILE

SANTIAGO, CHILE

CVALLEJOS3O@GMAIL.COM

\section{Presencia, olvido e insistencia. Comentario sobre la relación entre diseño y desarrollismo en Chile}

\author{
Presence, Oblivion and Insistence. Comment on the Relationship \\ Between Design and Developmentalism in Chile
}

Resumen. El presente texto se pregunta por la influencia que tuvo en Chile el desarrollismo económico en el ámbito cultural-simbólico, y cómo influenció, a su vez, el devenir del diseño local. Se indaga acerca del carácter multidisciplinar que manifestaron ciertas prácticas de diseño en Chile entre las décadas del 60 y 70 , y cuáles fueron algunos de los factores que precipitaron su desintegración como práctica cooperativa. Finalmente, el texto levanta un proceso reflexivo en torno a tres imágenes, intentando establecer un correlato político del contexto actual a la luz de lo que estas imágenes evidencian. Palabras clave: desarrollismo, diseño, huella, industria, político.

\begin{abstract}
The present text reflects on the influence that had the economic developmentalism within the Chilean cultural-symbolic field, and how it affected in turn, the becoming of local design. It inquires about the multidisciplinary character manifested in certain design practices in Chile between the 605 and 70 s, and which were the factors that precipitated its disintegration as a cooperative practice. Finally, the text raises a reflexive process concerning three images, intending to establish a political correlate on the current context under the light of what those images demonstrate.
\end{abstract}

Keywords: design, developmentalism, footprint, industry, political. 
1. Resultaría vano minimizar el aporte al desarrollo del lenguaje visual concreto en América Latina de Max Bill. Sin embargo, debemos recordar que parte importante de los directores que lo sucedieron en la Escuela de Ulm se distanciaron de las posturas originales al relativizar la atención a la dimensión estética que Max Billconcedía al diseño. Tomás Maldonado por ejemplo, quizás uno de los más radicales ulmianos, considera que las urgencias contextuales (políticas, económicas) imponían una premura que difícilmente daba espacio para consideraciones estéticas o cualquier influjo artístico presente en los procesos de diseño de la época.

\section{Materialidad, visualidad y desarrollismo}

Aproximadamente desde 1950 en adelante, en América Latina comienza a establecerse una lógica desarrollista. Como es bien sabido, al interior de este planteamiento económico, la confianza en el desarrollo de los países se sostenía en la aplicación de estrategias productivas que fomentaran la industrialización de las naciones. Industrialización que podemos comprender como la aplicación de los parámetros racionales, es decir, modernos, a los procesos de producción industrial. ¿Dónde radica el potencial político alojado en el desarrollismo?¿Qué consecuencias sociales trae consigo este planteamiento? Una de las cuestiones que persigue el desarrollismo consistía en desarticular la lógica económica imperante hasta la época; a saber, la relación centro-periferia, o mejor dicho, desarticular la relación entre países industrializados y países con economías primarias-extractivas. En el seno de Latinoamérica, la estrategia económica iba dirigida a industrializar las naciones, con el objetivo claro de instalar a la región en la retirada del subdesarrollo. Se trataba, entonces, de fracturar un discurso político-social-económico que regimentaba el devenir latinoamericano. Reconocemos aquí parte del potencial político (para aquel tiempo disruptivo), proveniente del desarrollismo. Sus implicancias sociales bien pueden ser rastreadas en el ámbito productivo, material, y continuar vibrando en el espectro simbólico. Indudablemente esta estrategia económica influye en la conformación de los regímenes representacionales. La economía altera a la visualidad, altera a la objetualidad. Un ejemplo a la mano de esto lo puede constituir la Bienal de São Paulo de 1951. La presencia del ulmiano Max Bill da buena cuenta de ello. Se trataba de instalar un nuevo lenguaje visual; de poner en contacto la visualidad de Brasil con la visualidad europea. Se trataba de modernizar el lenguaje de las artes e instalar a São Paulo en el centro cultural del mundo. Se perseguía la transformación de los paradigmas de conformación de la realidad. En este sentido, la noción tradicional de visualidad, es decir, la noción heredada (para el caso latinoamericano y chileno por ejemplo) del academicismo europeo que contenía el sacro espacio de las bellas artes, debía ser remecida. A este remezón estético contribuye Max Bill. La instalación de la geometría y la abstracción, elementos basales del lenguaje visual concreto, se presentan como las evidencias que funcionan como aval de nuestra aseveración. Con Unidad Tripartita, Bill gana el primer lugar en la categoría de escultura de la mencionada Bienal. Un ejemplo de economía de la forma provoca que aún hoy, el objeto permanezca atado a una cuota irremontable de actualidad, de atemporalidad. ${ }^{1}$

"La forma sigue a la función": esta suerte de axioma ulmiano define de muy buena manera el núcleo programático-productivo, es decir político, del diseño de la Escuela de UIm. Hay algo de implacabilidad de la forma, algo de cruda honestidad en la objetualidad ulmiana: los procesos de depuración formal, a la hora de proyectar diseño, son en sí mismos instancias políticas. Si una de las funciones del diseño es equipar el mundo, lo que se debe cuidar es que el utensilio permanezca en su condición, que no la abandone con un afán de protagonismo; la ausencia objetual debiera ser la protagonista en la órbita del utensilio, o lo que viene a ser lo mismo, el utensilio debe "diluirse" en su función. ¡Lo que interesa es que funcione! Esto no tiene que ver con producir objetualidades disminuidas en su dimensión estética: solo si comprendemos la estética como esteticismo, es decir, como reformulaciones cosméticas sin miras al componente funcional, estaríamos en condiciones 
de ubicar la producción ulmiana alejada de la esfera estética. Estética no es lo mismo que esteticismo; moderno no es igual a posmoderno.

La tradición de diseño de Ulm representa ciertos valores transversales de la modernidad. La racionalidad de los procesos, la marcada orientación social de sus producciones, la interconexión entre diseño e industria, conformaban una línea de actividad que se alineaba de buena forma a las directrices que inspiraron a los gobiernos latinoamericanos. Entre el 60 y 70 en Chile, el camino de reorientación económica desarrollista demandó la creación de centros de innovación tecnológica que proporcionaran nuevos puntos de impulso a una economía que luchaba por industrializarse. Si de lo que se trataba era de industrializar el país, qué mejor que el modelo programático ulmiano para realizar esta ambición. Ulm incorporaba soluciones de diseño a los procesos industriales; a una necesidad emergente, una solución consolidada.

En 1968, por solicitud del presidente Eduardo Frei Montalva, la OIT (Organización Internacional del Trabajo) trae a Chile a Gui Bonsiepe. Mano derecha de Tomás Maldonado en Ulm, Bonsiepe es requerido para que asesore a Sercotec (Servicio de Cooperación Técnica) perteneciente a coRfo (Corporación de Fomento de la Producción) en tareas tendientes a impulsar el desarrollo de la pequeña y mediana industria nacional. En ese contexto, Bonsiepe puede ser considerado uno de los agentes relevantes en el proceso de modernización industrial del país. Su influencia decantó no solo en la producción objetual concreta, sino que por sobre todo, el modelo productivo ulmiano, racionalizó los procesos industriales: desde la modificación del funcionamiento gerencial, pasando por la rearticulación de los procesos financieros y transformando las lógicas de comercialización, el enfoque sistémico del diseño ulmiano se corporiza al interior del sistema chileno. La presencia de Bonsiepe se mantuvo al interior del Gobierno de la Unidad Popular. Es así como en 1970 Fernando Flores, subgerente Técnico de CORFo, lo invita a dirigir el recién creado INTEC (Instituto de Investigaciones Tecnológicas de Chile). En este nuevo marco contextual socialista, la presencia de Bonsiepe aseguraba la definitiva orientación política del diseño en Chile: mediante su decidida incorporación a los procesos industriales, el diseño debía abocarse a solucionar las necesidades del consumo popular.

\section{IRMIR o sobre los insumos para la a integración plástica nacional}

IRMIR, Gres Cerámico. El gres cerámico IRMIR es inalterable, indesgastable e impermeable. La decoración y el dibujo del gres cerámico IRMIR sean para muros o pisos son eternos.

Gastone Marsanich funda IRMIR en 1948, una fábrica chilena que se abocaba a la producción de baldosas y mosaicos en vidrio. IRMIR actuará en el Gobierno de la Unidad Popular como uno de los principales proveedores para el Estado de materiales de recubrimientos de superficies, utilizados en construcción y en proyectos artísticos de emplazamiento urbano.

Ya a comienzos de los 60, durante el gobierno de Eduardo Frei Montalva se instala en Chile la preocupación por el entorno urbano. En este contexto (1965) nace la Corporación de Mejoramiento Urbano (CORMU), una empresa autónoma del Estado encargada de mejorar y reactivar zonas urbanas deterioradas, ejerciendo modificaciones radicales al entorno urbano que aspiraban a transformarse en norma de desarrollo territorial. Se trataba de 
modernizar la urbe guiados por el imperativo racionalista. Este proceso se alza como una crítica a la forma en que la modernidad se había implementado en Chile. CORMu se enfoca en la problemática social, específicamente en los problemas de crecimiento descontrolado y desigualdad social traducida en marginalidad e insalubridad urbana (Gámez Bastén, 2006).

Bajo la consigna modernizadora de la CORMU, lo que se perseguía no era tan solo la actualización física-matérica del casquete urbano: sino instalar una nueva forma de concebir lo urbano, es decir, una nueva forma de relacionarse con el entorno de la urbe, cuestión que estaría gobernada por un nuevo ánimo en donde la cooperatividad operaría como fuerza aglutinante de una nueva experiencia. Es así como a inicios de la década del 70, CORMU organiza un concurso para modernizar el paso bajo nivel de Santa Lucía, en Santiago. La consigna exigía que los proyectos que se presentaran tenían que considerar el trabajo cooperativo entre industria y arte.El proyecto ganador fue el del Grupo de Diseño Integrado en unión con la fábrica IRMIR. Carlos Ortúzar, Iván Vial y Eduardo Martínez Bonati -en 1971-, utilizan materiales de esta fábrica nacional para realizar el mural que se encuentra en el emplazamiento antes referido. Son más de $2.600 \mathrm{~m}$ de composición que bien puede encajar con los preceptos del arte óptico. Una superficie inmóvil se las arregla para generar sensación de movimiento. Pensada desde su inicio como una obra compenetrada con su lugar de emplazamiento, el mural remite su existencia a la experiencia del automovilista: está pensado para operar bajo la condicionante de la velocidad del automóvil, en donde el conductor no puede detenerse a "contemplar" la obra; quien conduce atiende "disipadamente" (tal y como piensa Benjamin en relación al flaneur parisino); subliminalmente podríamos decir, se cuela por el rabo del ojo una imagen fija que se despliega al interior del tráfico óptico. Entre otras cosas, lo relevante de esta obra está en su concepción: no hablamos de que el mural haya venido a "hermosear" la superficie del paso bajo nivel; el arte aquí no emerge en clave decorativa; tampoco lo hace el diseño, los cerámicos aquí utilizados no embellecen (única y exclusivamente) el hormigón armado sobre el cual se ubican. Estamos frente a una suerte de prodigiosa indefinición: no es solo industria, no es solo diseño, no es solo arte; es integración visual, mejor, integración plástica. Industria, diseño y artes visuales operando cooperativamente. El resultado, un emplazamiento urbano que manifiesta una notable economía figurativa, y una muy adecuada atención a los factores presentes en la experiencia estética que se hace propia del tránsito por dicho lugar.

\section{Remoción, huella y olvido. Sobre la insistencia política del diseño}

La Figura 1 corresponde a parte del patio central de las Torres de Tajamar, la Figura 2, corresponde a la Unidad Vecinal Providencia. El influjo moderno en ambas construcciones es evidente: en las Torres de Tajamar, tanto la altura como la utilización del hormigón desnudo lo transformaba en ejemplo arquitectural inédito; por su parte, la Unidad Vecinal Providencia, construida durante el Gobierno de Carlos Ibáñez del Campo, se alza como un ícono moderno por antonomasia, en donde se persigue rearticular la concepción relacional entre el habitante urbano y su entorno; el influjo de Le Corbusier es claro. Ambos complejos se corresponden históricamente. Esa correspondencia contextual está en la base de nuestro desarrollo.

En ambas imágenes lo que vemos es la marca que ha dejado el cerámico sobre la superficie en que se dispuso. Del cerámico en sí mismo nada 
sabemos; su presencia es trascendida por la marca que gracias al registro fotográfico se actualiza. La huella que observamos opera aquí como seña, no tan solo de un momento particular de la conjunción entre arte e industria, ni tampoco solo como una etapa relevante del diseño en Chile; la huella indica un pasado, un contexto vinculante, multidisciplinar y cooperativo que activó en Chile un enfoque industrial y creativo inéditos para la época. Sobre todo la huella marca la ausencia, es decir, una falta, el post de un impacto. La huella opera en potencia, como registro, registro de una fuerza que ha logrado imprimir sobre una superficie un cierto impacto; estamos frente a una superficie contactada; la fuerza que ha hecho el contacto es, en este caso, el resultado entre la comunión arte e industria. El contexto de emergencia de esta fuerza mancomunada ha sido referido anteriormente; bástenos enfatizar su raigambre racionalista, modernizadora y su aspiración social de igualitarismo. Toda huella manifiesta al menos una duplicidad en el ámbito del sentido: por un lado, remarca la ausencia física que la genera, por otro, refiere el espesor simbólico del contexto que ha pasado a pérdida. Es esta irreductible duplicidad la que nos ha hecho detenernos en estas imágenes. Aquella, se yergue como exigencia básica de todo mirar; estas, son siempre el resultado de una intencionalidad política. La decisión de encuadre de las que son fruto las imágenes referidas (Figura 1 y Figura 2) encuentran eco en la escritura aquí desplegada. Tiene que ver con una cuestión de resistencia; resistencia, antes que todo y especialmente, al olvido. El registro fotográfico opera aquí como insumo para un ejercicio de rememoración histórica, cuando menos, necesario. La ausencia del cerámico gres de IRMIR, deja en evidencia un vacío alterado por la marca de fábrica del propio material: la simplicidad, la economía figural de su logo puede trabajar aquí como una metáfora. El logo al que hacemos alusión da buena cuenta de los imperativos estéticos (que siempre son políticos) que enmarcaban el contexto desarrollista al que la producción fabril cerámica de IRMIR se remite. Hay depuración formal, hay claridad visual, el logo funciona: ya sea para denotar modernidad, ya sea para asegurar actualidad, el modo en que se resuelva el logo de IRMIR lo hace acreedor de una respetuosa atención. Tras la cerámica ausente nos encontramos con el vacío; con el vacío alterado por lo indeleble de la marca IRMIR. Intentando ampliar nuestra mirada sobre el asunto, proponemos pensar esta ausencia como metáfora. Diremos que aquel vacío del cual hablamos no ha podido ser llenado en la actualidad. Si aquello que llenó el espacio que hoy contemplamos desnudo fue el producto de la cooperatividad multidisciplinar creativa, esta sustancia parece bastante debilitada, hoy por hoy, para configurarse como materia lo suficientemente espesa como para intentar completar espacio alguno. ¿Qué pasa en las artes locales hoy en día? ¿Cuál es la relación de la industria nacional con el campo de producción artística? ¿Cuál es el estado actual del sector industrial chileno? Estas cuestiones ganan lugar cuando visualizamos la orientación económica terciarizada que ha adquirido Chile luego del Golpe de Estado; mejor dicho, el súbito direccionamiento neoliberal por el que la economía nacional ha hecho recorrer al país. La relación del arte con la industria, las prácticas de diseño integrado, la concepción racionalista en el ámbito del diseño acabaron de golpe.

La ausencia del cerámico IRMIR da cuenta de un mundo, progresivamente diezmado, sistemáticamente debilitado y acabado de un golpe. Vestigio de una organización política, social y económica diferente, la huella a la que aludimos es comprendida como signo identitario de los efectos de una
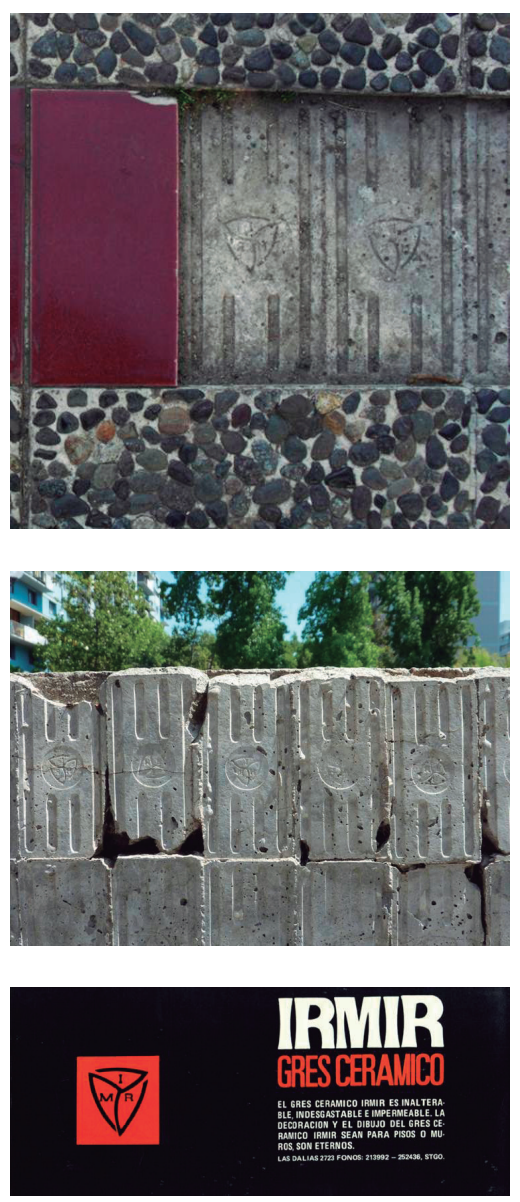

Figuras 1, 2 y 3 . Gres cerámico IRMIR. Fuente: Archivo de Rodrigo Vera Manríquez. 
estrategia de borradura, olvido y abandono. Sin embargo, precisamente aquí, en este punto, es en donde se hace visible la performatividad política de lo que se pretende olvidar; las manifestaciones de un tipo particular de diseño, proveniente de un contexto histórico igualmente particular, siguen insistiendo en el presente aunque, hasta ahora, solo en negatividad.

IRMIR desaparece en 1976, dos años después de ser vendida. Chile experimenta los vertiginosos efectos de su incorporación al carro del sistema del capital. Los efectos de esa decidida e ingobernable aceleración pueden ser rastreados hasta hoy.

Las imágenes de las que hablamos bien pueden concebirse como una tentativa de arqueología urbana: para intentar comprender el presente es necesario recurrir al pasado (reciente); para comprender qué ha pasado con la trinidad Arte/Industria/Diseño, quizás sea útil echar una mirada a los años 60 y 70 en Chile; para comprender las causas de la desfragmentación de la misma, quizás sea necesario revisar los 70 y 80 en Chile; para tener noticia de la consumación de la disgregación trinitaria, quizás debamos observar desde los noventa hasta la actualidad.

A inicios del 2013, el Centro Cultural Gabriela Mistral (GAM) trajo a Chile una exposición con parte importante de la obra del Atelier Mendini; a inicios de 2014, también en el GAM, se expuso parte de la obra de Ettore Sottsass y el Grupo Memphis. Poseedores de una estrategia política distinta y distante de la lógica del diseño moderno que aquí hemos mencionado, Atelier Mendini y Memphis, en un ánimo encasillante, pueden ser comprendidos como representantes de la lógica posmoderna. ¿Por qué se decide actualizar una tradición de diseño internacional de corte posmoderna? La pregunta no tiene tanto un ánimo peyorativo como sí uno crítico-político. ¿Qué incide en la decisión de proporcionar visibilidad a un tipo de diseño por sobre otro? ¿Por qué sí Memphis y no cierta vajilla producida por Fanaloza? ¿Por qué Atelier Mendini síy los cerámicos de IRMIR no? ¿Por qué no cimentar una relación de la ciudadanía con el diseño comenzando por actualizar matrices de producción locales provenientes de un pasado reciente?

El diseño moderno al cual nos hemos referido aquí aspiraba a incidir, material y simbólicamente, en la estructuración del cotidiano; repensar las relaciones posibles entre diseño e industria, comprometer socialmente la praxis del diseñador en la sociedad chilena, todos efectos perseguidos por la animosidad reformista. Reunir los frentes vitales y creativos (otra forma de comprender el anhelo de implicación del diseño con lo cotidiano) fue el horizonte hacia el cual se dirigía el Chile de aquel entonces. Hoy en día, ese horizonte nos ha caído encima y el anhelo de reunir la esfera creativa con la vida ha sido finalmente realizado. El punto es que dicha realización no se ha dirigido al cumplimiento de los ideales modernos; el diseño, siendo eminentemente moderno, ha padecido de la modernización. Modernización que ha transformado la matriz económica a escala planetaria hasta instalarnos en el centro de un modelo tardocapitalista. El diseño, en su dimensión posmoderna, es uno de los agentes relevantes a la hora de revitalizar y de mantener la apariencia de novedad en las mercancías. Sin embargo, es desde el campo mismo del diseño, desde donde puede levantarse una perspectiva crítica a la concepción del diseño como agente primario de la reificación tardocapitalista. 


\section{Bibliografía}

Bonsiepe, G. y Fernández, S. (2008). Historia del Diseño en América Latina y el Caribe. San Pablo: Edgard Blucher.

Devalle, V. (2009). La travesía de la forma. Emergencia y consolidación del diseño gráfico (1948-1984). Buenos Aires: Paidós.

Foster, H. (2004). Diseño y delito y otras diatribas. Madrid: Akal.

Gámez Bastén, V. (2006). El pensamiento urbanístico de la Cormu (1965-1976). Urbano, 9(13), 9-18.

Heskett, J. (2008). El diseño en la vida cotidiana. Barcelona: Gustavo Gili.

Martín Juez, F. (2005). Contribuciones para una antropología del diseño. Barcelona: Gedisa.

Palmarola, H. (2002). Diseño Industrial Estatal en Chile 1968-1973. Conferencia presentada el 12 de Noviembre al ciclo Testimonios de la Modernidad. Facultad de Arquitectura, Diseño y Estudios Urbanos, Pontificia Universidad Católica de Chile, Santiago de Chile. Sparke, P. (2010). Diseño y Cultura. Barcelona: Gustavo Gili. 